\title{
Position paper on passive sampling techniques for the monitoring of contaminants in the aquatic environment - Achievements to date and perspectives
}

\author{
Miège Cécile ${ }^{1,{ }^{*}}$, Mazzella Nicolas ${ }^{2}$, Allan Ian ${ }^{3}$, Dulio Valeria ${ }^{4}$, Smedes Foppe ${ }^{5,6}$, Tixier Céline ${ }^{7}$, \\ Vermeirssen Etienne ${ }^{8}$, Brant Jan ${ }^{9}$, O'toole Simon ${ }^{10}$, Budzinski Hélène ${ }^{11}$, Ghestem Jean-Philippe ${ }^{12}$, \\ Staub Pierre-François ${ }^{13}$, Lardy-Fontan Sophie ${ }^{14}$, Gonzalez Jean-Louis ${ }^{15}$, Coquery Marina ${ }^{1}$, \\ Vrana Branislav ${ }^{5}$
}

${ }^{1}$ Irstea, UR MALY (Freshwater Systems Ecology and Pollution research unit), 5 rue de la Doua, CS70077, 69626 Villeurbanne Cedex, France

${ }^{2}$ Irstea, UR REBX (Water networks, purification and quality unit), 50 Avenue de Verdun, Gazinet, 33612 Cestas Cedex, France

${ }^{3}$ NIVA, Section 312, Gaustadalleen 21, 0349 Oslo, Norway

${ }^{4}$ INERIS - Direction Risques Chroniques, Rue Jacques Taffanel, Parc technologique ALATA, 60550

Verneuil-en-Halatte, France

${ }^{5}$ Masaryk University, Faculty of Science, Research Centre for Toxic Compounds in the Environment RECETOX, Kamenice 753/5, 62500 Brno Czech Republic

${ }_{7}^{6}$ Deltares, PO. Box 85467, 3508 AL Utrecht, The Netherlands

7 Ifremer, RBE-BE-LBCO, rue de l'lle d'Yeu, B.P. 21105, 44311 Nantes, Cedex 3, France

${ }^{8}$ Swiss Centre for Applied Ecotoxicology Eawag-EPFL, 8600 Dübendorf, Switzerland

${ }^{9}$ Cefas, Pakefield Road, Lowestoft, Suffolk NR34 9DX, UK

${ }_{11}^{10}$ Environmental Protection Agency, Richview, Clonskeagh Road, Dublin 14, Ireland

${ }^{11}$ Université Bordeaux 1, EPOC-UMR 5805 CNRS, LPTC, Bat. A12, 351 crs de la Libération, 33405

Talence, France

${ }^{12}$ BRGM, Laboratory Division, 3 avenue Claude Guillemin, 45060 Orléans, Cedex 02, France

${ }^{13}$ ONEMA, 5 allée Félix Nadar, 94300 Vincennes, France

${ }^{14}$ LNE, DMSI, 1 rue Gaston Boissier, 75724 Paris, Cedex 15, France

${ }^{15}$ Ifremer, RBE-BE-LBCM, B.P.330, Zone Portuaire de Brégaillon, 83507 La Seyne/mer Cedex, France

* Corresponding author : Cécile Miège, email address : cecile.miege@irstea.fr

\begin{abstract}
:
This paper, based on the outcome of discussions at a NORMAN Network-supported workshop in Lyon (France) in November 2014 aims to provide a common position of passive sampling community experts regarding concrete actions required to foster the use of passive sampling techniques in support of contaminant risk assessment and management and for routine monitoring of contaminants in aquatic systems. The brief roadmap presented here focusses on the identification of robust passive sampling methodology, technology that requires further development or that has yet to be developed, our current knowledge of the evaluation of uncertainties when calculating a freely dissolved concentration, the relationship between data from PS and that obtained through biomonitoring. A tiered approach to identifying areas of potential environmental quality standard (EQS) exceedances is also shown. Finally, we propose a
\end{abstract}


list of recommended actions to improve the acceptance of passive sampling by policy-makers. These include the drafting of guidelines, quality assurance and control procedures, developing demonstration projects where biomonitoring and passive sampling are undertaken alongside, organising proficiency testing schemes and interlaboratory comparison and, finally, establishing passive sampler-based assessment criteria in relation to existing EQS.

\section{Highlights}

- Monophasic polymer PS are recommended for hydrophobic substances. Adsorption-based PS for hydrophilic substances provide semi-quantitative data. The development of new PS for ionic and highly hydrophilic substances is required. PS reflect the contaminant levels to which biota is exposed in waters. - PS allow to rank areas with risk of EQS exceedance before monitoring in biota.

Keywords : passive sampling, water framework directive, monitoring programmes, priority substances, emerging substances, environmental quality standards

\section{Introduction}

For two decades, several passive sampling devices have been developed for the monitoring of organic and inorganic contaminants in aquatic environments. These passive samplers (PS) enable the improvement of limits of quantification (LOQ) by accumulation and concentration of contaminants over long-term exposure. Moreover, when they are used in the integrative phase of uptake (i.e. integrative samplers), time-weighted average (TWA) concentrations over the exposure period can be derived, leading to a better representativeness of measurements.

Such passive sampling techniques have been recommended in the European Commission Guidance Document on surface water chemical monitoring [1], then in the Water Framework Directive (WFD) daughter Directive 2013/39/EU [2] as complementary methods to improve the level of confidence in water monitoring data in comparison with conventional spot sampling. PS are assumed to have a positive influence on the future design and output of monitoring programmes in the context of the WFD and the Marine Strategy Framework Directive (MSFD). However, some barriers still remain that prevent regulatory acceptance and actual implementation of these tools for routine monitoring of contaminants in aquatic systems.

In order to endorse PS use in monitoring programmes, several actions have been conducted, including interlaboratory studies (ILS) to evaluate the performances of passive sampling methods with a focus on (i) hydrophobic substances in situ [3], (ii) hydrophobic substances in laboratory (ECLIPSE project, [4]), (iii) priority substances in situ (AQUAREF, www.aquaref.fr, [5]), and (iv) emerging substances in situ (NORMAN network, http://www.norman-network.net/?q=Home, with the Joint Research Centre's Institute for Environment and Sustainability, JRC-IES, [6]). Moreover, a NORMAN Expert Group meeting on "Linking Environmental Quality Standards and Passive Sampling" was organised in July 2013 in Brno (CZ) to discuss the possible routes for the implementation of passive sampling in regulatory monitoring for checking of compliance with Environmental Quality Standards (EQS) for WFD priority and river basin-specific substances. And, in collaboration with the International Commission for the Protection of the Danube River (ICPDR) and within the framework of the Joint Danube Survey (JDS3) in 2013, the NORMAN network launched a study to develop and test a methodology for continuous screening of large rivers 
using passive sampling. The aim was to assess the applicability of a temporally and spatially integrative sampling approach as a water quality monitoring tool for various substances. The results of this study have been published recently [7].

In November 2014, a "Workshop on Passive Sampling techniques for monitoring of contaminants in the aquatic environment", was organised jointly by the NORMAN network and AQUAREF, at Irstea, Lyon, France. This workshop brought together experts involved in passive sampling activities carried out by the NORMAN network and beyond. They discussed the state of the art and defined the strategy and a roadmap of further actions to be fostered by NORMAN, for 2015 and beyond, to improve implementation of passive sampling techniques in environmental monitoring.

The present paper is addressed to scientists and to water managers and decision-makers at river basin, national and European level. The aim of this paper is to provide a common position, as discussed at the workshop in Lyon, of the passive sampling community experts regarding concrete actions required to improve the use of passive sampling techniques in support of risk assessment and risk management and to point to ways of overcoming the remaining barriers to regulatory acceptance and actual implementation of these tools for routine monitoring. Particular attention is given to organic contaminants, for which various types of PS can be used according to their hydrophobicity (sections 3.1. and 3.2.). The discussion on PS for monitoring programmes in water and biota (sections 3.3 and 3.4) also includes the case of metals, as sampled with the generally accepted PS: Diffusive Gradient in Thin Films (DGT) [8].

\section{Method}

The first day of the meeting focused on discussions between scientific experts on technical issues surrounding the features and performance of passive sampling techniques. Participation on the second day was also open up to stakeholders and embraced the applicability of PS in regulatory monitoring programmes in the aquatic environment (WFD - MSFD, OSPAR Convention, etc.).

The workshop was organised in four sections which reflect the recurrent questions and challenges identified by decision-makers as regards the use of passive sampling techniques for environmental monitoring:

1. Which PS are suitable for monitoring hydrophobic organic compounds in water? Can we expect to obtain accurate time-weighted average (TWA) concentrations with these PS?

2. Which PS are suitable for monitoring hydrophilic organic compounds in water? Can we expect to obtain accurate time-weighted average (TWA) concentrations with these PS?

3. What is the role of passive and grab sampling approaches in monitoring programmes? Are data obtained by passive sampling comparable with those from grab sampling?

4. What role can passive sampling play in support to chemical monitoring in biota?

The conclusions presented in this paper are organized following these 5 successive items. Parts 1 and 2 focus on organic contaminants, whereas parts 3 and 4 cover all contaminants, including metals.

\section{Results and discussion}




\subsection{Which passive samplers are suitable for monitoring hydrophobic compounds in water?}

Various types of PS are available for hydrophobic compounds: the Semi-Permeable Membrane Device (SPMD, biphasic system), silicone rubber and Low Density PolyEthylene (LDPE) strips (monophasic systems) are the most commonly used [8].

It is not possible to recommend a single specific PS. Rather, PS calibration data should satisfy certain performance or quality standard criteria, and uptake and release processes should be in agreement with theory. Recommending a specific PS would also lead to a loss of information and prevent an improvement of existing techniques or new developments.

SPMD is a biphasic PS (a polyethylene membrane filled with lipid), and can therefore generally be considered more complex than monophasic polymers concerning sample processing in the laboratory and modelling of contaminant uptake mechanisms. Given these constraints, it is expected that the use of monophasic samplers will be favoured over the use of SPMD. Nevertheless, the use of SPMD for more than 20 years has generated numerous laboratory and field data. Moreover, it is at present the only standardised and commercially available PS for hydrophobic compounds.

Even so, for practical reasons, monophasic polymers (e.g. silicone rubber, LDPE) appear to be the most suitable PS for sampling of hydrophobic compounds.

Monophasic polymers can be of different qualities and made of different materials; but at the moment, there are no standard commercial products available. It was therefore unanimously agreed that there is a need for commercial supplies of standard monophasic PS.

Suitable polymers should meet the following criteria:

- the uptake of the polymers must be based on absorption (not adsorption) and sampler/water partition coefficients for the compounds of interest should be sufficiently high in order to allow good performance in terms of substance accumulation;

- the diffusion coefficients of target substances inside the polymer should be sufficiently high so water boundary control dominates the uptake process, even under severe turbulence conditions. This allows the uptake process to be calibrated from the release of Performance Reference Compounds (PRC, i.e. a sort of internal standards) that are dosed prior to deployment $[9,10]$.

For each new monophasic polymer, sufficient diffusion should be confirmed and partition coefficients should be determined either independently or through cross-calibration against a polymer with already known partition coefficients. Such a polymer (e.g. silicone) could serve as a reference material for sampler cross-calibration.

For accurate analysis of PS, there is also a need for certified reference materials (CRMs) of polymers used in passive sampling containing the most widely monitored and regulated compounds. Preparation of such CRMs could be the role of the European JRC for Reference Materials and Measurements (IRMM) and/or of the National Metrology Institutes (NMIs).

The application of PS in waters requires knowledge of polymer-water partition coefficients $\left(K_{\mathrm{pw}}\right)$ and knowledge that diffusion coefficients $\left(D_{\mathrm{p}}\right)$ in the polymer are sufficiently high, both 
for substances of interest and for those used as PRC. When commercial PS products and CRMs become available, their routine use for monitoring compounds whose diffusion and partition coefficients (and their uncertainty) have been published will not require additional calibration experiments by end-users. The use of accurate $K_{\mathrm{pw}}$ constants, PRC for measurement of in situ exchange kinetics, and the application of validated uptake models are sufficient for accurate measurements of contaminant concentrations in waters using PS.

Thus, in order to support the use of PS, it is important to:

- Develop harmonised guidelines, in particular for :

$\circ$ the measurement of polymer-water partition coefficients $\left(K_{\mathrm{pw}}\right)$;

$\circ$ the measurement of substance diffusion coefficients $\left(D_{\mathrm{p}}\right)$ in PS polymers;

$\bigcirc$ the definition of criteria for an appropriate application of PRC;

$\circ$ the definition of suitable and validated models for calculation of water concentration from PS.

- Perform interlaboratory studies to improve validation of PS for routine use.

As to the latter, it is recommended that interlaboratory studies aimed at validation of PS for routine use should be designed as two-step exercises, in which Step 1 is the Proficiency Test (PT) for the analysis of the contaminants in the extracts of PS, and Step 2 is an interlaboratory study for intercomparison of PS field-deployment and analysis of contaminants in PS, including estimation of water concentration.

Only skilled laboratories (i.e., those that succeeded in Step 1) should be allowed to participate in Step 2. For the choice of contaminants, the focus should be on hydrophobic WFD Priority Substances and other substances (including the new Priority Substances) for which robust analytical methods already exist (for analysis in PS exposed in the aquatic environment).

With respect to the influence of temperature and salinity, $K_{\mathrm{pw}}$ values used for calculation of freely dissolved concentrations are usually determined for $\mathrm{T}=20^{\circ} \mathrm{C}$ and salinity $=0 \%$. Workshop participants concluded that there is no need to correct $K_{\mathrm{pw}}$ for temperature nor salinity, since EQS values are not corrected for the effects of these parameters, when used for compliance monitoring (to be noted that there are specific EQS in marine waters). Moreover, the approach using $K_{\mathrm{pw}}$ without correction provides more conservative water concentration estimates (higher concentrations are estimated in scenarios with low temperature and high salinity); such estimates are therefore more protective when referring to compliance with EQS (worst case scenario).

\subsection{Which passive samplers are suitable for monitoring of hydrophilic compounds in water? Can we expect to obtain accurate time weighted average (TWA) concentrations with passive sampling?}

Various types and configurations of PS exist today for hydrophilic compounds: the Polar Organic Chemical Integrative Sampler (POCIS) (e.g. with different membranes and sorbent phases), the Chemcatcher and the Empore disks are the most commonly used [8]. At present, it is not possible to recommend a preferred specific PS for sampling of hydrophilic compounds.

It was acknowledged that at present the mechanisms of uptake and release of hydrophilic substances from water into these adsorption-based PS are not fully understood. The exchange 
of compounds between the PS and the aqueous phase can often be considered an anisotropic process. Consequently, it is generally not possible to use the release of PRC to calibrate the uptake rate and allow calculation of time weighted average (TWA) water concentrations for a wide range of compounds. Nonetheless, PRC should be used as surrogates to check that exposure conditions (e.g. temperature, salinity, water flow) are within the limits for which the laboratory derived the calibration data (quality controls).

Currently, adsorption-based PS for hydrophilic compounds allow only semi-quantitative information to be obtained. This is because of the uncertainty in applying laboratory-based sampling rates to in situ field conditions. However, when confidence intervals of estimated TWA concentration are available, these PS data could be used for EQS compliance checking. One of the possible approaches to apply PS data for assessing compliance with a regulatory limit involves the calculation of the upper $90 \%$ confidence limit of the PS-derived TWA concentration. Accurate analyses and the use of an equivalent volume of water sampled by the PS smaller than the actual sampled volume to calculate water concentrations would ensure that estimated TWA concentrations are an overestimate of actual concentrations and a robust use of PS. The good status cannot be considered as achieved if the calculated upper TWA concentration limit exceeds the EQS. This is possible for substances for which linear uptake is confirmed for the period of exposure.

Poulier et al. (2014) [11] recently proposed a method to determine confidence intervals for each TWA concentration estimate by POCIS, over a period of one year (Figure 1). The means of maximum and minimum limits of these confidence intervals are defined as MAX and MIN, respectively. Thereafter, the MAX and MIN values are compared to the AA-EQS (annual average EQS) and good chemical status is considered to be achieved if MAX is lower than the AA-EQS (Figure 1).

Figure 1: Proposed procedure to use POCIS data for surveillance monitoring (from Poulier $e t$ al., 2014, [11]).

Understanding the uptake mechanism of polar compounds into adsorption-based PS is the first and most important issue that needs to be resolved in order to reduce the currently observed uncertainty in passive sampling data. New solutions have to be found to simplify PS construction to an effective minimum. In this process, it is possible that some of the traditionally applied passive sampling designs will have to be abandoned (e.g. application of membranes in PS, which often cause undesired complications of the uptake mechanism).

Even if PS tools for hydrophilic substances still need developments and adaptations, guidelines describing how to conduct PS calibrations are required. In particular, such guidance should define a common set of metadata and calibration conditions (temperature, water flow, type of the exposure system, type of water) to be reported together with the obtained sampler calibration parameters. All this information is required for the assessment of the possible relationship between the observed variability in available calibration data and the exposure conditions used in calibrations [12].

In situations where the effect of environmental conditions on the PS performance (especially the sampling rate) in the field cannot be either determined or controlled, application of laboratory-derived calibration parameters will always introduce a systematic error into derived water TWA concentrations. When water concentrations are calculated from passive 
sampling data, expected variability of applied calibration parameters should be included in the calculation of the reported concentration. The value and uncertainty of applied sampling rates and the approach for calculation of uncertainty should also be reported. More generally, the reporting of passive sampling data requires improved practice, focusing particularly on the data and models used to estimate water concentrations from contaminant masses sorbed into the PS.

In contrast with spot sampling, PS provides time-integrated concentrations of pollutants. If the uncertainty of water concentrations obtained from PS is lower than the variability of environmental concentrations, data obtained by PS represent the contamination situation in the water body as well as or better than the low frequency spot sampling (e.g. based on 4 to 12 sampling times per year) that is currently used in compliance monitoring for the WFD.

Previous interlaboratory studies (including the AQUAREF ILS [5] in 2010 and NORMAN ILS [6] in 2011) showed that accurate analysis of certain hydrophilic substances (pesticides, pharmaceuticals, steroid hormones, perfluorinated compounds) remains a challenge for a number of laboratories. Inaccurate analyses contributed significantly to the observed high variability of water concentrations derived from PS data which cannot be attributed to inadequacies of the PS process. It was therefore recommended to organise further intercomparison studies. As for hydrophobic compounds, in order to ensure validation of the different parts of the PS process, future intercomparison studies should be designed as twostep exercises, where Step 1 is the PT for analysis of contaminants in extracts of PS, and Step 2 is Interlaboratory comparisons for PS field-deployment and analysis of contaminants in PS. Only skilled laboratories (i.e., those that succeeded in Step 1) should be allowed to participate in Step 2. For the choice of contaminants, the focus should be on WFD Priority Substances and other hydrophilic substances (including new Priority Substances) for which robust analytical methods exist (in PS exposed in real water).

Finally, workshop participants identified the need to develop PS for ionic and highly hydrophilic compounds (e.g. glyphosate).

\subsection{Passive versus grab sampling approaches in monitoring programmes}

Passive sampling measures the dissolved phase concentration of a contaminant (and not the whole water concentration, as required by Directive 2013/39/EU [2]). As a result, passive sampling cannot be used today to assess compliance with EQS for all organic contaminants under the WFD, but only for moderately polar to polar organic compounds (with $\log K_{\mathrm{ow}}<5$ ) where the concentration in the water column is not dominated by the fraction adsorbed to colloids and particles in water. On the other hand, passive sampling is recommended in the European Commission Guidance Document on surface water chemical monitoring [1] and in the Directive 2013/39/EU [2] as a complementary method to improve the quality of the assessment and as a resource saving measure. In this regard, passive sampling could be used in conjunction with investigative monitoring as a risk-based screening tool to evaluate the presence or absence of chemical contaminants, to identify sources of pollution when the concentration levels (and therefore the required limits of detection) are extremely low or when the source of pollution is intermittent.

Passive sampling can also be employed in trend monitoring both as a qualitative and a quantitative tool. PS offer added value compared to grab sampling when applied as an "early- 
warning tool" to detect increasing (or decreasing) trends. Exceedance of defined threshold values could be used to trigger further monitoring using conventional sampling techniques, e.g. grab sampling and/or biota monitoring.

Some practical advantages of passive sampling can be highlighted:

- low limits of detection and quantification can be achieved, especially with samplers for hydrophobic compounds;

- in situ sample preconcentration is possible and the handling of large water volumes can be avoided (thereby allowing lower costs for transport and storage in comparison with conventional spot sampling, and easier sampling in remote locations);

- thanks to higher stability of the sampled compounds, it is possible to allow prolonged sample storage;

- analysis of samples can be delayed and, if needed, combined to composite samples;

- unlike water samples, sorbents or extracts of PS are more suitable for long term storage in specimen banks.

As to the quality of the information obtained from PS measurement results:

- information obtained with PS is representative of an extended time period; this integrated information is more relevant to describe the status of a water body than the information which can be obtained with spot sampling;

- only freely dissolved compounds are sampled: for hydrophobic compounds, PS provide a measure directly proportional to the chemical activity of the contaminant of interest in the medium being sampled;

- PS allow a reduction in the effect of blank contamination, since the integrative character of sampling allows concentrations in exposed PS to be found that are significantly higher than levels found in blanks.

There is still a need for pilot field studies to gain experience and demonstrate the usefulness and relevance of passive sampling strategies compared to grab sampling. Such demonstration studies should be designed to show the difference between conventional monitoring (i.e. 4 to 12 spot water samples / year, or integrative biota monitoring for hydrophobic compounds and metals) and a new, more relevant and practical concept using PS. The study should aim to demonstrate that a TWA concentration via PS is more representative and relevant - compared to conventional monitoring - for the characterisation of the chemical status of water bodies. In France, such a demonstration exercise is planned by AQUAREF for the next WFD monitoring cycle, in close connection with policy-makers, stakeholders and end-users (water agencies). This action could be extended to the European level through NORMAN network activity. In the Netherlands, local water authorities have been using PS for monitoring POPs in surface and coastal waters in parallel with monitoring in mussels [13] for more than a decade. In addition, demonstration studies applying passive sampling in parallel with biota monitoring and led by the Environment Agency in the UK are under way.

Indeed, regulatory implementation of PS requires decision-makers to be convinced of the need to globally change the current monitoring and compliance checking concept under the WFD. The relevance of the signal obtained by passive sampling (integrative sampling, relation of TWA concentrations with the environmental risk to aquatic organisms) should be stressed. Such a change in the monitoring concept recently took place in the anti-doping sector in sports where controls are now performed on hair (integrative information) rather than in urine (punctual information). 
It is acknowledged that there is much more experience of large scale PS application for marine water monitoring than for freshwater monitoring. It is therefore necessary to better share this experience between the two expert communities. For example, the three-level approach in place within OSPAR, which consists of drafting of guidance documents, organisation of proficiency tests (via QUASIMEME, http://www.quasimeme.org) and definition of water quality assessment criteria, could also be applied to continental waters [14].

In order to allow improved compilation and comparison of measurement data from PS, experts agreed that it is necessary to define a common and harmonised set of metadata that should accompany the measurement results to be reported in the literature and / or in databases. It is recommended that such a harmonised set of metadata should be included in the next update of the ISO 5667/23 standard [15].

A central European repository (database) would be useful to better share PS monitoring data. This database should gather information on the PS used, the conditions of deployment, the analytical method, the method to treat the results, the concentration in the PS and the estimated water TWA concentration. There is already a NORMAN template for collecting PS data (used for passive sampling data collection from the Joint Danube Survey 3 [7]). This template could be used by the PS community as the basis of a possible upgrade before final validation and adoption as a common data collection template.

Finally, to facilitate communication and dissemination, there is a need to adopt harmonised terminology within the PS research area.

Some knowledge gaps remain as regards the battery of passive sampling devices suitable for very hydrophilic and/or ionisable substances, for some priority substances (e.g. PFOS and mercury) for which biota EQS exist, and for substances with extremely low EQS in water (e.g. dichlorvos, dicofol and heptachlor) [2].

\subsection{Applicability of passive sampling in support of chemical monitoring in biota}

With the recent update of the EQS Directive 2013/39/EU [2], there is a demand for cost efficient monitoring tools that could support data obtained from chemical monitoring in biota. The newly introduced $\mathrm{EQS}_{\text {biota }}$ for hydrophobic compounds call for the use of analytical methods that meet the requirements of the QA/QC Directive (2009/90/EU) [16]. With these $\mathrm{EQS}_{\text {biota }}$, protection of human health via consumption of fishery products, and protection of predators against secondary poisoning were also introduced as new protection goals. Hence, these $\mathrm{EQS}_{\text {biota }}$ bring new challenges in the design of monitoring programmes and data interpretation for compliance checking and assessment of trends (for example, the need to normalise biota data based on lipid content, trophic magnification factor etc.).

According to the European Commission technical guidance for the implementation of EQS biota $_{\text {in }}$ [17], PS can be applied in a tiered approach to identify or rank areas of potential EQS exceedance (Figure 2, [18]). In such a tiered approach, trigger values (i.e. threshold concentrations, exceedance of which triggers the second tier, monitoring of biota) are needed.

Figure 2: Proposed tiered approach to identify potential EQS exceedance using PS (from P. Whitehouse, 2014 [18]). 
Experts discussed further possibilities of the application of PS, beyond the current recommendation of the European Commission, to support or replace chemical monitoring of hydrophobic compounds and mercury in biota.

Despite the recommended normalisation of biota monitoring data prior to chemical status assessment, the establishment of temporal and spatial trends of bioaccumulating compounds is still expected to be complicated by the inherent variability of the sampled aquatic organisms. Even if "active biomonitoring" for biota (caged organisms) offers some practical solution for marine waters and more recently for continental waters [17,19], experts believe that the inherent variability of passive sampling data can be much better controlled, which presents the main advantage of the abiotic sampling approach.

Experts agreed that passive sampling cannot predict actual concentrations of priority compounds in biota. Passive sampling data can predict the concentrations that would be determined in biota (lipid) if the organism were at thermodynamic equilibrium or steady state with the environment. However, deviations from equilibrium cannot be easily forecasted because of the complexity of uptake processes, trophic magnification, growth dilution, seasonal influences and the "home-range" of the species, which result in a large variability of accumulation of chemical contaminants in biota. As a result, bioconcentration factor (BCF) and bioaccumulation factor (BAF) data reported in the literature are extremely variable. The application of these BCF and BAF literature values to predict concentrations of contaminants in biota from passive sampling derived aqueous concentrations thus lead to a large variability.

In spite of those limitations, experts are of the opinion that PS reflect very well the contaminant levels to which biota are exposed in their natural environment. The same contaminant trends (in time and space) could be observed both in biota data and in passive sampling data (as demonstrated for example by the long-term observation of PS vs mussels performed in the Netherlands for marine waters [13]). Experts concluded that passive sampling is a suitable tool to determine spatial and temporal trends, with lower inherent data variability compared to chemical monitoring in biota. The expert view is that (except for secondary poisoning purposes) measuring contaminant levels in waters can be more appropriate for assessing aquatic biota exposure than measuring their concentration in the organisms. For example, some compounds that are actively metabolised would not be found in organisms (or only at low concentrations), although organisms were exposed to them (e.g. polycyclic aromatic hydrocarbons in fish). Nonetheless, it must be noted that recent studies showed that active biomonitoring in gammarids could provide useful data for metals exposure in freshwater systems [20].

If $\mathrm{EQS}_{\text {biota }}$ were set only to protect human health from exposure via consumption of fish, there would be no role for passive sampling in water monitoring. In this case it would be sufficient to assess that levels of contaminants in fish used for human consumption do not exceed the defined thresholds. However, since the definition of EQS ${ }_{\text {biota }}$ also embraces other protection goals, including protection of aquatic life, PS can still play a significant role in WFD monitoring.

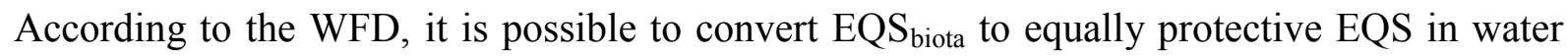
$\left(E_{\text {QS }}{ }_{\text {water }}\right)$ and use such standards in regulatory monitoring. The uncertainty of PS concentrations of the most hydrophobic priority substances in water is sufficiently low to 
allow in principle for a comparison with $\mathrm{EQS}_{\text {water }}[3,21]$. This is possible especially because limits of quantification that are achievable by passive sampling for those hydrophobic compounds are lower than the respective EQSs.

From the uptake of hydrophobic pollutants by PS, the freely dissolved concentration is estimated, which represents the driving force for bioconcentration in organisms. PS thus enable the in situ determination of hydrophobic bioaccumulative organic compounds that organisms at the lowest trophic level are exposed to.

The results from passive sampling can also be converted to lipid-based concentrations for an organism considered at equilibrium with the environment to which the sampler was exposed (using lipid-polymer partition coefficients). The advantage of expressing results on a lipid basis is, besides being more closely related to concentrations in biota, that it is an easier unit to communicate to regulators and the public, since it is difficult for a layman to understand that concentrations in the range of $\mathrm{fg} / \mathrm{L}$ to $\mathrm{pg} / \mathrm{L}$ in water can pose a hazard. Lipid-polymer partition coefficients will be needed for all substances of interest (i.e. those with existing $\mathrm{EQS}_{\text {biota }}$ ); and for those for which values already exist, further validation may be required.

A major recommendation resulting from this workshop is that, on the sites across Europe where biota monitoring is undertaken for WFD or OSPAR purposes, biota monitoring should be as far as possible complemented by PS exposures. This will help develop the much needed datasets to improve our understanding of bioaccumulation factors. Parallel exposures of PS with biota monitoring (ideally, including multiple trophic levels) at a number of sites in Europe (with different exposure levels) will enable assessment of the variability of BAFs used in the conversion of $\mathrm{EQS}_{\text {biota }}$ to $\mathrm{EQS}_{\text {water }}\left(\mathrm{BAF}=\mathrm{C}_{\text {biota }} / \mathrm{C}_{\text {water }}, \mathrm{C}_{\text {water }}\right.$ is the freely dissolved concentration from PS, BAF could be established at different river basins). When such variability is known and acceptable, biota monitoring could be subsequently replaced by monitoring with PS for compliance checking.

\section{Conclusions}

This paper summarises the outcome of discussions that were held during a NORMAN Network- workshop in Lyon (France) in November 2014. We aimed to provide commonlyagreed recommendations to enable the future use of passive sampling for regulatory monitoring of contaminants in aquatic environments. We hope these steps will contribute to increase acceptance of passive sampling by policy-makers. A number of concrete actions required to advance the use of passive sampling techniques in support of contaminant risk assessment and management have been identified:

- Monophasic polymers (e.g. silicone rubber or low density polyethylene) are recommended as the PS of choice for hydrophobic, non-ionised organic substances and the community unanimously agrees that there is a need for commercial supplies of monophasic passive samplers.

- Currently, for hydrophilic organic substances, adsorption-based samplers (e.g. POCIS) provide semi-quantitative data only and further research is needed to either a) reduce uncertainty of measurement of existing devices, or b) develop a new sampler design with a simpler (and better controlled) contaminant uptake mechanism. Another viable route for application of these devices in regulatory monitoring, for EQS compliance checking of WFD Priority Substances, is to establish intervals of estimated TWA 
concentrations and to compare the maximum and minimum limits of these confidence intervals to the AA-EQS values.

- For the future, the development of new PS for ionic and highly hydrophilic compounds is required.

- Uncertainty associated with passive sampling-derived aqueous concentrations can be evaluated and taken into account when PS are used for trend and compliance monitoring. This is confirmed by experience from previous interlaboratory studies, which clearly showed that for certain groups of emerging compounds, inaccurate analysis, rather than the passive sampling technique, is still the main cause of the observed high variability of the results reported by the laboratories. Future intercomparison studies should be organised so that they include different steps in order to ensure validation of each critical part of the sampling and analytical process (i.e. analysis of the contaminants in the extract, PS-field deployment and analysis of the contaminants in the PS, including calculation of water concentration).

- One major feature of passive sampling compared to grab sampling is that PS provide TWA concentration results. These integrated TWA measurement data provide more representative and relevant information for characterisation of the chemical status of water bodies than conventional monitoring (mean values of 4 to 12 spot samples) data. However, such a shift demands a radical change in the regulatory procedure with which water agencies and decision-makers are familiar. The launch of field studies where the two approaches, the conventional one and the PS approach, would be applied in parallel on a number of selected sites, is highly recommended in order to convince decision-makers that it is advantageous to make this shift.

- PS reflect the contaminant levels to which biota have been exposed in their natural environment.

- As regards chemical monitoring of hydrophobic priority substances in biota, PS can be applied in a tiered approach to identify or rank areas of potential risk of exceedance of EQSs before chemical monitoring in biota. Replacement of chemical monitoring in biota by PS can also be envisaged. The main advantage of such an alternative route is that PS can ensure a lower inherent variability of the concentration data compared to biota monitoring data. PS cannot predict actual concentrations of priority compounds in biota, but passive samplers reflect well the contaminant levels to which biota have been exposed in their natural environment. Since the definition of EQS $S_{\text {biota }}$ is not limited to protection of human health but also to the protection of aquatic life, and in consideration of the fact that the WFD allows EQS biota $_{\text {to }}$ be converted in equally protective $\mathrm{EQS}_{\text {water, }}$ concentration data obtained with PS can be considered compatible with the protection objectives set by $\mathrm{EQS}_{\text {biota. }}$.

- In consideration of all the above, steps to be undertaken to convince policy-makers to accept passive sampling in regulatory monitoring are:

○ Drafting of guidelines and clear Quality Assurance/Quality Control rules;

- Running of demonstration projects/case studies with passive sampling undertaken alongside spot sampling and biota monitoring, in order to demonstrate their applicability for compliance monitoring purposes;

○ Organisation of proficiency testing (PT) schemes and interlaboratory exercises for passive sampling in water;

○ Development of assessment criteria in relation to EQSs.

\section{References}


[1] European Commission, Guidance Document $\mathrm{n}^{\circ} 19-$ Common implementation strategy for the Water Framework Directive (2000/60/EC). Guidance on surface water chemical monitoring under the Water Framework Directive. Technical Report (2009) $025,132 \mathrm{p}$.

[2] Directive 2013/39/EU of the European Parliament and of the Council amending Directives 2000/60/EC and 2008/105/EC as regards priority substances in the field of water policy, Off. J. Eur. Union. (2013) L 226: 1-17.

[3] I.J. Allan, K. Booij, A. Paschke, B. Vrana, G-A. Mills, R. Greenwood, Environmental Science and Technology 43 (2009) 5383.

[4] R. Jacquet, C. Miege, F. Smedes, C. Tixier, J. Tronczynski, A. Togola, C. Berho, I. Valor, J. Llorca, B. Barillon, P Marchand, M. Coquery, Chemosphere. 98 (2014) 18.

[5] C. Miege, N. Mazzella, S. Schiavone, A. Dabrin, C. Berho, J.-P. Ghestem, C. Gonzalez, J.-L. Gonzalez, B. Lalere, S. Lardy-Fontan, B. Lepot, D. Munaron, C. Tixier, A. Togola, M. Coquery, Trends in Analytical Chemistry. 36 (2012) 128.

[6] B. Vrana, F. Smedes, R. Prokeš, R. Loos, N. Mazzella, C. Miege, H. Budzinski, E. Vermeirssen, T. Ocelka, A. Gravell, S. Kaserzon, submitted in Trends in Analytical Chemistry.

[7] B. Vrana, F. Smedes, T. Rusina, K. Okonski, I. Allan, M. Grung, K. Hilscherova, J. Novák, P. Tarábek, J. Slobodník. In: I. Liška, F. Wagner, M. Sengl, K. Deutsch, and J. Slobodník (Eds.). Vienna: ICPDR - International Commission for the Protection of the Danube River, (2015) 304. http://www.danubesurvey.org/results

[8] B. Vrana, G.A. Mills, I.J. Allan, E. Dominiak, K. Svensson, J. Knutsson, G. Morrison, R. Greenwood, Trends in Analytical Chemistry, 24/10 (2005) 845.

[9] T.P. Rusina, F. Smedes, J. Klanova, K. Booij, I. Holoube, Chemosphere. 68 (2007) 1344.

[10] T.P. Rusina, F. Smedes, M. Koblizkova, J. Klanova, Environmental Science and Technology. 44 (2010) 362.

[11] G. Poulier, S. Lissalde, A. Charriau, R. Buzier, F. Delmas, K. Gery, A. Moreira, G. Guibaud, N. Mazzella, Science of the Total Environment. 497/498 (2014) 282.

[12] N. Morin, C. Miege, J. Randon, M. Coquery, Trends in Analytical Chemistry. 36 (2012) 144.

[13] F. Smedes. In: Greenwood, R. Mills, G.A. Vrana, B. (Eds.). Passive Sampling Techniques in Environmental Monitoring, Elsevier, Amsterdam, (2007) 407.

[14] OSPAR Commission, London Publication, $\mathrm{n}^{\circ} 379 \quad$ (2008). http://www.ospar.org/documents/dbase/publications/p00379/p00379 cemp assessmen t manual.pdf

[15] ISO 5667-23, Water quality - Sampling - Part 23, (2011) 23 p.

[16] Directive 2009/90/EC of 31 July 2009 laying down, pursuant to Directive 2000/60/EC of the European Parliament and of the Council, technical specifications for chemical analysis and monitoring of water status. Off. J. Eur. Union. (2009) L 201: 36-38.

[17] European Commission. Guidance document $n^{\circ} 25$. Common implementation strategy of the Water Framework Directive (2000/60/EC). Guidance on chemical monitoring of sediment and biota under the Water Framework Directive. Technical Report, (2015) $74 \mathrm{p}$

[18] P. Whitehouse. Personal communication, Workshop on "Passive Sampling as a monitoring tool for emerging chemicals", Dublin (2014).

[19] J-P. Besse, O. Geffard, M. Coquery, Trends in Analytical Chemistry. 36 (2012) 113.

[20] J-P. Besse, M. Coquery, C. Lopes, A. Chaumot, H. Budzinski, P. Labadie, O. Geffard, Water Research, 47/2 (2013) 650. 
[21] R. Lohmann, K. Booij, F. Smedes, B. Vrana, Environmental Science Pollution Research. 19 (2012) 1885. 
Step 1 : Analysis of the POCIS exposed monthly in the water body

Step2 : $C_{\text {PocIS }}$ are corrected with the appropriate factors to account for the lower and upper limits of the POCIS uncertainty.

Cpocis

Step 3 : Calculation of the average concentration MIN and MAX

Step4 Water diagnosis

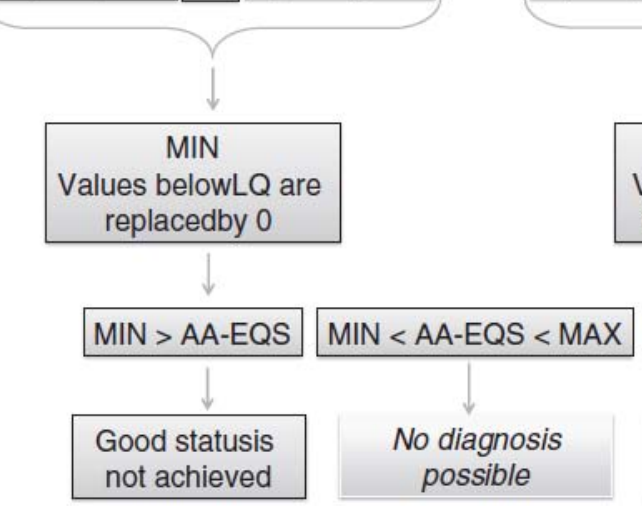

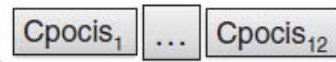
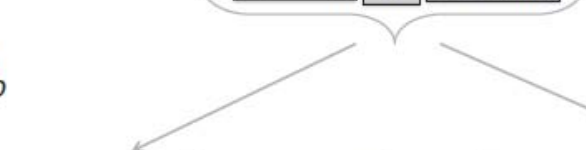

is $_{1} \min$

... .pocis $_{12} \mathrm{~min}$

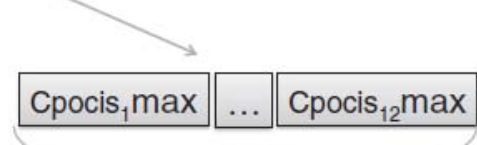

MAX

Values belowLQ are replacedby the $L Q$

Figure 1: Proposed procedure to use POCIS data for surveillance monitoring (from Poulier et al., 2014, [11]). 


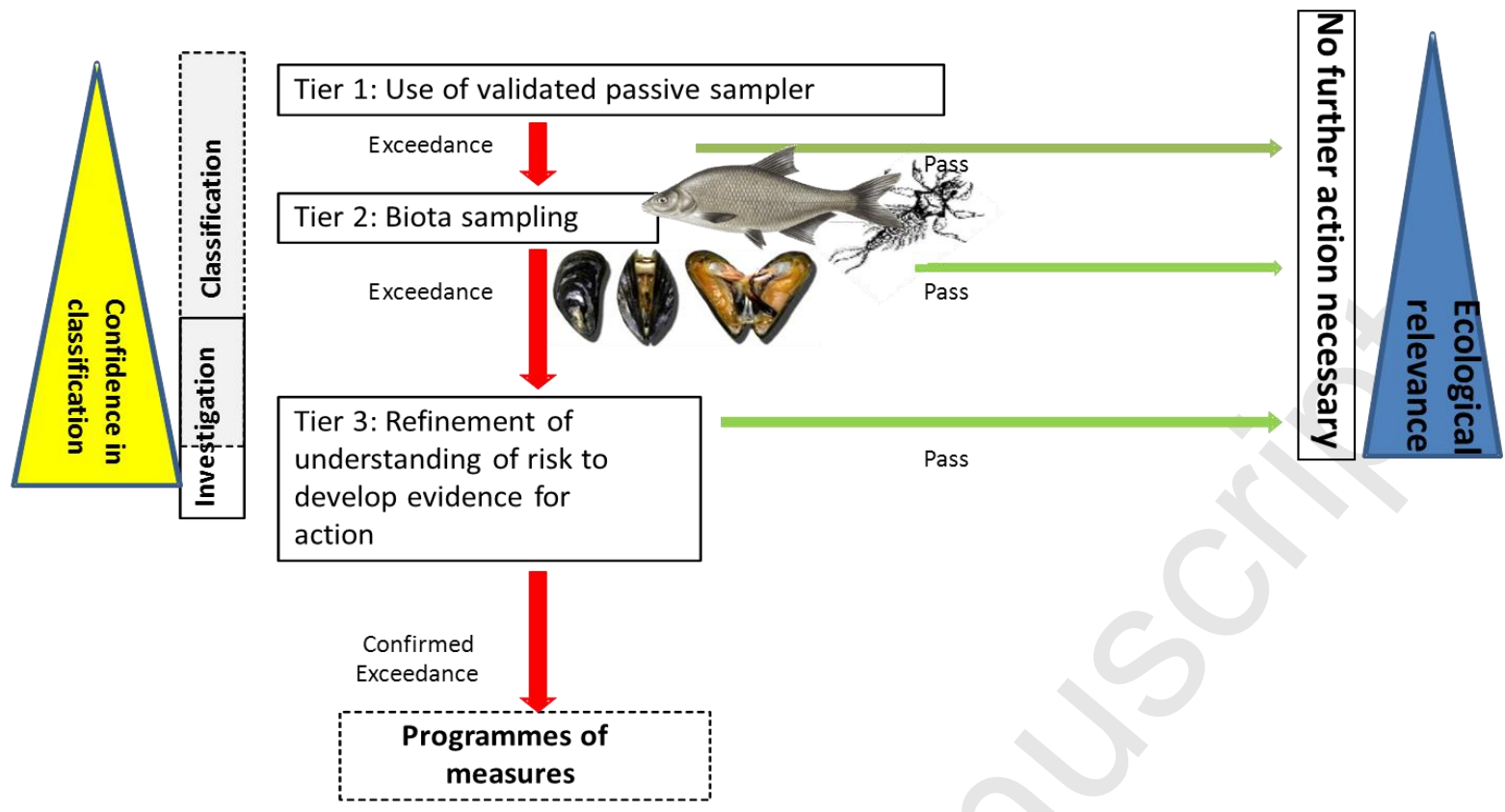

Tier 1: Validated PS "screen" where $\mathrm{EQS}_{\text {biota }}$ available $\rightarrow$ Presence/absence. Calibration to validate "nondetection" = no risk to biota. Positive detection $\rightarrow$ Biota screening

Tier 2: Risk to predators/humans via food chain. Collect larger numbers of small organisms. Human health based EQS $\rightarrow$ sample Fish/biota. $<\mathrm{EQS}_{\text {biota }}=$ STOP

Tier 3: Refinement of risk and increasing confidence in assessment (increased sampling programme, geographical aspects etc.)

Figure 2: Proposed tiered approach to identify potential EQS exceedance using PS (from P. Whitehouse, 2014 [18]). 